\title{
Mastery Sentences: A Window into the Interplay between Word Knowledge Types
}

\author{
Andrew Gallacher \\ Kysushu Sango University \\ doi: http://dx.doi.org/10.7820/vli.v04.1.gallacher
}

\begin{abstract}
This study investigates students' productive knowledge of high-frequency vocabulary using a word knowledge framework. A sample of more than 300 written "mastery sentences" was analyzed and coded for errors made at the meaning level of the target word, as well at the usage level. These sentences were categorized into three groups, based on students' English proficiency, which roughly translates to low-to-mid A2, mid-to-high A2, and low B1 on the Common European Framework of Reference. Preliminary findings indicate that while word knowledge at the meaning level improves with proficiency, knowledge at the usage level appears to plateau once students reach a mid-level of proficiency. Further investigation as to why this may be the case indicates that although higher level students tend to make roughly an equal number of grammatical and collocation-type mistakes compared to their mid-level counterparts, they do so in attempts to use richer, less frequent vocabulary in their mastery sentences. These preliminary findings suggest that, in the spirit of mastery, students may be making more errors as they test the limits of newly acquired vocabulary. Future research will further investigate this hypothesis.
\end{abstract}

\section{Background}

Until recently, most vocabulary teaching and learning strategies have prioritized receptive skills over productive skills (Webb, 2005), mainly because productive skills have proven more difficult to elicit (De la Fuente, 2002). This is especially true in the Japanese EFL context, where students receive little-to-no opportunity for productive engagement with the language, both in and out of the classroom. By the time students reach university, they may be able to translate word-to-word meaning pretty efficiently but often still have difficulty using these words in sentences of their own creation. For this reason, studies have begun to stress the importance of incorporating productive activities into vocabulary instruction and acquisition (Laufer \& Paribakht, 1998; Ryan, 1997; Schmitt, 1998; Schmitt \& Meara, 1997).

One of the more popular ways of integrating productive elements into vocabulary study is to have students write sentences for new words they are learning (see Al-Murtadha, 2013; Folse, 2006; Masson, 2012; Pichette, de Serres, \& Lafontaine, 2011). The argument for doing this is that by moving away from one-to-one lexical processes and focusing more on production of semantic chunks, the students will begin to engage with other "word knowledge types" (Nation, 
1990, p. 31 - see below), which in turn will help improve upon other productive skills on the way toward overall vocabulary mastery (Schmitt, 2010).

Word knowledge types (Nation, 1990):

- the meaning(s) of the word

- the written form of the word

- the spoken form of the word

- the grammatical behavior of the word

- the collocations of the word

- the register of the word

- the associations of the word

- the frequency of the word

How divergent is knowledge of definitional meanings of L2 words from knowledge of usage of these same words in original sentences? The current study attempts to examine the relationship between knowledge of word meaning, proficiency, and vocabulary usage (i.e. the other word knowledge types) through a qualitative examination of a year's worth of "mastery sentences" produced by students at three levels of L2 proficiency. This preliminary, qualitative investigation is intended as a first step toward future quantitative studies on the topic.

\subsection{Mastery Sentences}

The mastery sentence method of vocabulary study is one component of a larger integrated-learning curriculum designed to improve students' English listening, speaking, reading, and writing abilities at a university in Southern Japan (for more information about the program, please see Anderson and Wilkins (2014) and Masson (2013)). For their vocabulary study, students are required to study 400 of the 1600 most commonly used words in the British National Corpus (for more information please visit: http://www.natcorp.ox.ac.uk/) per semester, totaling 800 in a year. These words are split into 10 lists composed of 40 words each, which are then assigned as weekly homework over the course of a 10-week period. From each list, students are asked to identify the words with which they are least familiar (with a minimum of 20 being set) and use them to comprise vocabulary notebooks as recommended by (Folse, 2006).

Students are asked to include in their vocabulary notebooks the following: the correct written form of each word; its most common two meanings in Japanese; some associated words and/or collocates of each word; and an exemplary mastery sentence demonstrating one of the two meanings of the word. After completing this homework each week, students are given a quiz on 10 randomly chosen words from the previous week's list. On the quiz, students are required to write the 10 words chosen, along with a mastery sentence for each.

In essence, mastery sentences are elaborate sentences that indicate word meaning by employing as many of the other word knowledge types as possible. In this way, the target words become contextually bound to the sentence as a whole. 
A successful mastery sentence thus becomes one in which the target word, if removed, could only be replaced by a direct synonym (Masson, 2012).

For example: banana

(1) Monkeys love to peel and eat ripe yellow bananas.

In previous studies measuring students' perceptions of the mastery sentence approach it was found that, despite being difficult for them to understand and put into practice, students believed the technique to be beneficial in (1) building their vocabulary knowledge and (2) improving their overall ability to compose sentences (Al-Murtadha, 2013; Masson, 2012).

\section{Methodology}

\subsection{Participants}

Three first-year Japanese private university students (age 19) enrolled in their school's Four Skills English program were chosen to participate in this study. In order to conceal their identities, each of the participants have been given a pseudonym. Their details are as follows.

\subsubsection{Hank (TOEIC score $=400$ )}

Hank (male) is majoring in International Affairs with a focus in Asian Relations. His 400 Test of English for international communication (TOEIC) score is roughly equivalent to a low-to-mid A2 level on the Common European Framework of Reference (CEFR). Hank had an 85\% attendance rate in the Four Skills program and contributed "the minimum amount to pass" throughout the course, thus receiving an overall "C" grade. For the purposes of this study, Hank exemplifies a "low" level Four Skills student.

\subsubsection{Nancy (TOEIC score $=490)$}

Nancy (female) is majoring in Fine Arts with a focus on design. As a design student, Nancy's overall course load tends to be more demanding than the others. As a result, time management occasionally proved problematic for Nancy, although her resilience and participation in class allowed her to pass with a "B" grade. Nancy's 490 TOEIC score puts her at a mid-to-high A2 level on the CEFR. She had an $87 \%$ attendance rate in the Four Skills program and is considered a "mid" level Four Skills student for the purposes of this research.

\subsubsection{Cindy (TOEIC score $=635)$}

Born and raised in Okinawa (arguably a more Anglicized part of Japan), Cindy (female) entered university with a greater English fluency than most of her peers. Her 635 TOEIC score is considered a low B1 level on the CEFR. Furthermore, Cindy's major in International Affairs with a focus on English Communication, along with her continued enthusiastic participation in class, is demonstrative of her personal interest in learning English. She had a $90 \%$ 
attendance rate in the Four Skills program and achieved an "A" grade overall. Cindy is considered a "high" level Four Skills student.

\subsection{Procedure}

This research was based on mastery sentences (MS) produced by students as a regular component of their Four Skills coursework. The participants were asked if the vocabulary-related material they produced throughout the year could be used for the current research purposes. Once permission was obtained, the participants' mastery sentence-based vocabulary quizzes were isolated, collated, and copied in preparation for qualitative assessment (see Appendix 1 for an example of the raw data).

With the tested vocabulary categorized by part of speech (noun, verb, adjective), students' mastery sentences were then scored for correct meaning (M) and usage (U) of tested words. Meaning was deemed correct when auditors (interrater reliability $=85 \%$ ) were satisfied that a sentence provided enough context to properly convey the underlying concept or "core meaning" (see Schmitt, 2010, p. 27) of a target item. Conversely, meaning was considered incorrect when: (a) participants failed to produce a sentence for the target item altogether; (b) the sentence they produced did not adequately convey the underlying concept (i.e. the example was not a mastery sentence); or (c) the sentence conveyed a meaning of the target item that is not conventionally associated with that word.

Usage was considered correct when words were used within clauses that were both grammatically correct and contextually appropriate (i.e. displayed proper use of connotation, register, and collocation). Restricting this evaluation to clauses was done in order to avoid penalizing students that made usage errors unrelated to the target words. Usage was marked as incorrect when clauses were either (a) grammatically flawed, (b) contextually inappropriate, (c) both grammatically flawed and contextually inappropriate, or (d) non-existent.

Occasionally, there were instances in which sentences were too short or vague for the auditor to determine with a degree of confidence whether or not the student knew the meaning of the word (e.g., "There is death near animals."). These cases were classified as "insufficient data" and removed from the analysis. The remaining data were then tabulated to compare proportions of correct usage and meaning by student level and part of speech.

\section{Results}

Combined, participants had far more instances of correct meaning than correct usage (see Table 1), which was also true for each level of proficiency (see Table 2) and part of speech (see Table 3).

Table 1. Overall Percentages of Correct Usage and Meaning

\begin{tabular}{ll}
\hline Usage & 38 \\
Meaning & 71 \\
\hline
\end{tabular}


Table 2. Overall Percentages of Usage and Meaning by Level

\begin{tabular}{lccc}
\hline & Low & Mid & High \\
\hline Usage & 28 & 41 & 43 \\
Meaning & 53 & 70 & 85 \\
\hline
\end{tabular}

Table 3. Percentages of correct Usage and Meaning by Level and Part of Speech

\begin{tabular}{lccc}
\hline & Low & Mid & High \\
\hline Noun & & & \\
Usage & 16 & 33 & 45 \\
Meaning & 47 & 70 & 89 \\
Verb & & & \\
Usage & 29 & 48 & 43 \\
Meaning & 58 & 74 & 86 \\
Adjective & & & \\
Usage & 21 & 34 & 34 \\
Meaning & 56 & 63 & 78 \\
\hline
\end{tabular}

Note: Meaning was shown to increase with proficiency while usage appeared to plateau between the midand high-level learners (see Figure 1).

To investigate this further, 15 mastery sentences in which students had correct meaning but incorrect usage were isolated for both the mid- and high-level students and analyzed using Lextutor's Vocabprofile, found on the website: http://www.lextutor.ca/. The results of this analysis yielded profiles for both the mid- and high-level learners showing the frequency of vocabulary each student used in mastery sentences with correct meaning but incorrect usage (see Table 4).

They indicate that although the higher level student had a comparable percentage of incorrect word usages, the sentences they produced used less frequent vocabulary. Given this, it is possible that the risks they took in their sentence production led to a comparable proportion of usage errors, despite their overall higher proficiency. Table 5 illustrates this further with example mastery sentences written by the mid- and high-level participants.

In these examples, the mid-level student gains more correct usage points by relying on simpler language, as indicated by the use of higher frequency words and the first-person subjunctive. Conversely, the higher level learner is caught dropping articles and mistaking verb forms while attempting to use much less frequent vocabulary in much more difficult ways. For example she wrote common occurrence rather than the correct collocation in this context (a common occurrence). However, it is commendable that she attempted to use this relatively infrequent collocation containing an abstract noun (occurrence) at all. Had the learner attempted a simpler sentence using a more concrete noun as the object (e.g., cats are common 


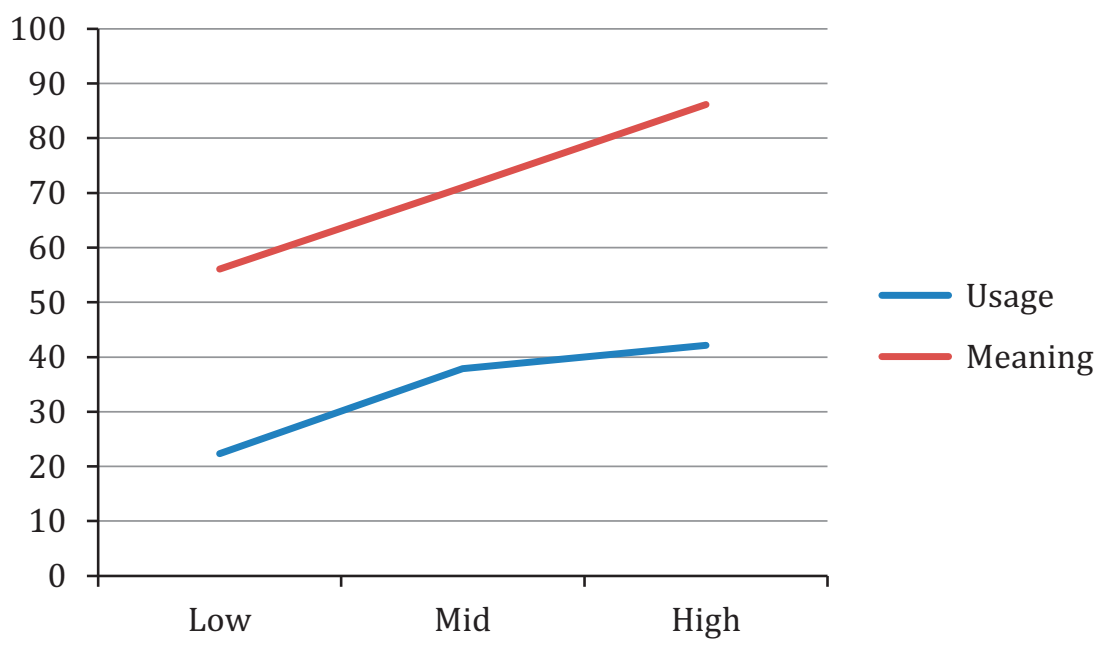

Figure 1. Usage and meaning by proficiency.

Table 4. Frequency of Vocabulary in Mastery Sentences with Correct Meaning but Incorrect Usage

\begin{tabular}{lcc}
\hline Freq. level & Mid & High \\
\hline K-1 words & 83.54 & 78.31 \\
K-2 words & 9.15 & 10.24 \\
K-3 words & 3.66 & 3.01 \\
K-4 words & - & 1.81 \\
K-5 words & - & 0.6 \\
K-6 words & 1.22 & 0.6 \\
Off-list: & 2.44 & 5.42 \\
Total & $164(100)$ & $166(100)$
\end{tabular}

Note. Table gives percentages of tokens in each frequency band.

Table 5. Example Mastery Sentences by Mid- and High-level Learners

\begin{tabular}{lll}
\hline & Target word & \multicolumn{1}{c}{ Example sentences } \\
\hline $\begin{array}{l}\text { Mid-level (correct usage and } \\
\text { correct meaning) }\end{array}$ & first name & My first name is Nancy. \\
& spoon & $\begin{array}{l}\text { I usually use a spoon when I eat } \\
\text { soup. }\end{array}$ \\
$\begin{array}{l}\text { High-level (incorrect usage and } \\
\text { correct meaning) }\end{array}$ & common & $\begin{array}{l}\text { A squall is common occurrence } \\
\text { in the tropical regions. }\end{array}$ \\
& strategy & $\begin{array}{l}\text { The government have to decide } \\
\text { strategies about decrease a } \\
\text { crime. }\end{array}$ \\
\hline
\end{tabular}


pets), she likely would have been marked correct for usage on this word. In this respect, it could be argued that the learner's higher proficiency acted as an impediment in regards to her ability to demonstrate correct usage.

\section{Conclusions}

In keeping with findings by Schmitt (1998) and Schmitt and Meara (1997), it is clear that knowledge of word usage trails that of knowledge of word meaning, regardless of proficiency. Interestingly, however, gains in knowledge of word meaning were not matched by relatively equal gains in knowledge of word usage. Instead the mid- and high-level students had roughly equal difficulty with word usage, despite the fact that the higher level student demonstrated knowledge of substantially more word meanings.

Subsequent analysis of the frequencies of words used in the mastery sentences produced by the mid- and high-level students suggested that this could possibly be a result of the higher level student attempting to use a richer range of language in her mastery sentences, which could have resulted in an equivalent proportion of usage errors. This suggests that, when writing mastery sentences, some higher level students may try to use more of the language they have learned. Thus, it may be that in the spirit of mastery, these learners may commit more errors as they test the limits of their vocabulary knowledge.

As educators, we should be encouraging of this experimentation in such cases, as the increased errors can be seen as opportunities for corrective feedback for learners that is level appropriate, and that learners are ready for. From a research perspective, it is apparent that further investigation into the nature of interaction between word knowledge types is greatly needed.

\section{References}

Al-Murtadha, M. (2013). Investigating the impact of sentence writing on second language vocabulary acquisition. Vocabulary Education \& Research Bulletin, $2(2), 2-3$.

Anderson, C. J., \& Wilkins, S. (2014). The four skills and advanced reading and writing syllabi. Kyushu Sangyo University Language Education and Research Center Journal, 9, 63-74.

De la Fuente, M. J. (2002). Negotiation and oral acquisition of L2 vocabulary. Studies in Second Language Acquisition, 24(1), 81-112. doi:10.1017/ S0272263102001043

Folse, K. S. (2006). The effect of type of written exercise on L2 vocabulary retention. TESOL Quarterly, 40, 273-293. doi:10.2307/40264523

Laufer, B., \& Paribakht, T. S. (1998). The relationship between passive and active vocabularies: Effects of language learning context. Language Learning, 48, 365-391. doi:10.1111/0023-8333.00046

Masson, M-E. (2012). Student feedback regarding the use of "mastery sentences. Vocabulary Education \& Research Bulletin, 1(1), 5-6. 
Masson, M-E. (2013). The development of the Four Skills course: An introductory course in the career English program. Kyushu Sangyo University Language Education and Research Center Journal, 8, 48-65.

Nation, I. S. P. (1990). Teaching and learning vocabulary. New York, NY: Newbury House.

Pichette, F., de Serres, L., \& Lafontaine, M. (2011). Sentence reading and writing for second language vocabulary acquisition. Journal of Applied Linguistics, 32(5), 1-18. doi:10.1093/applin/amr037

Ryan, A. (1997). Learning the orthographical form of L2 vocabulary - a receptive and productive process. In N. Schmitt \& M. McCarthy (Eds.), Vocabulary: Description, acquisition and pedagogy (pp. 181-198). Cambridge: Cambridge University Press.

Schmitt, N. (1998). Tracking the incremental acquisition of second language vocabulary: A longitudinal study. Language Learning, 48, 281-317. doi:10.1111/1467-9922.00042

Schmitt, N. (2010). Vocabulary in language learning. Cambridge: Cambridge University Press.

Schmitt, N., \& Meara, P. (1997). Researching vocabulary through a word knowledge framework: Word associations and verbal suffixes. Studies in Second Language Acquisition, 19(1), 17-36. doi:10.1017/S0272263197001022

Webb, S. (2005). Receptive and Productive Vocabulary Learning. Studies in Second Language Acquisition, 27(1), 33-52. doi:10.1017/S0272263105050023 


\section{Appendix 1 Mastery Sentence - Student Quiz Example.}

\begin{tabular}{|c|c|c|c|}
\hline & \multirow{2}{*}{ complain / } & He wants to complain about his school rules. & -4 \\
\hline & & I & \\
\hline \multirow{2}{*}{2} & \multirow{2}{*}{ Solve } & Police officers should solve any problems. & C \\
\hline & & & \\
\hline \multirow{2}{*}{3} & \multirow{2}{*}{ curious / } & Childrens are curious about many things. & 0 \\
\hline & & & \\
\hline \multirow{2}{*}{4} & \multirow{2}{*}{ 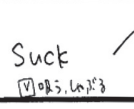 } & I an orange juice with a straw & $x$ \\
\hline & & & \\
\hline \multirow{2}{*}{5} & \multirow{2}{*}{ uncomfortable } & This chair is very uncomfortable to sit for me. & $A$ \\
\hline & & & \\
\hline \multirow{2}{*}{6} & \multirow{2}{*}{ 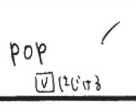 } & I always listering pop music & $x$ \\
\hline & & A ballon was poped suddenly. & \\
\hline \multirow{2}{*}{7} & \multirow{2}{*}{ Senior } & We have to give a seat in a train or bus when the serior person gets on 14 . & $\Delta$ \\
\hline & & & \\
\hline \multirow{2}{*}{8} & \multirow{2}{*}{ Strategy } & The government should make some strategy to reduce the car accident. & A \\
\hline & & & \\
\hline \multirow{2}{*}{9} & \multirow{2}{*}{$\begin{array}{c}\text { pretend } \\
\text { 3.: }\end{array}$} & I didn't pretend that he came to my house. & $\Delta$ \\
\hline & & I pretended that I didn't natice him because I hate him. & \\
\hline \multirow{2}{*}{10} & \multirow{2}{*}{ 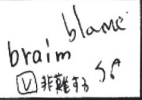 } & When I failed something. I blame ryself. & $x$ \\
\hline & & & \\
\hline
\end{tabular}

